\title{
Mechanical simulation study of postoperative displacement of trochanteric fractures using the finite element method
}

\author{
Atsuo Furui, Nobuki Terada and Kazuaki Mito
}

\begin{abstract}
Background: Femoral trochanteric fractures are common among older adults. In the reduction of trochanteric fractures, acquiring the support of the anterior cortex at the fracture site on lateral view immediately after surgery is important. However, even if the cortical support is acquired, postoperative displacement due to the loss of this support often occurs. This study aimed to investigate local stress distribution in several trochanteric fracture models and to evaluate risk factors for postoperative displacement using the finite element (FE) method.

Methods: Displaced two-fragment fracture models with an angulation deformity at the fracture site and a nondisplaced two-fragment fracture model were constructed. The models with an angulation deformity were of two types, one with the proximal fragment directed backward (type A) and the other with the proximal fragment rotated forward from the femoral neck axis (type B). Thereafter, FE models of the femur and a sliding hip screw mounted on a $135^{\circ}$ three-hole side-plate were constructed. A 2010-N load was applied to the femoral head, and a 1086-N load was applied to the greater trochanter. Under this condition, the maximum value of the von Mises stress distribution and the amount of displacement of the femoral head vertex in the distal direction were investigated.
\end{abstract}

Results: A larger maximum stress value at the medial femoral neck cortex and a higher amount of displacement in the distal direction were particularly recognized in type A models. These results indicate that microstructural damage was larger in type A models and that type A fracture alignment may be particularly related to fracture collapse and subsequent postoperative displacement.

Conclusion: Even if support of the anterior cortex at the fracture site on lateral view is acquired immediately after surgery, caution is necessary for cases in which the proximal fragment is directed backward in the postoperative displacement from the viewpoint of the biomechanics of the FE method.

Keywords: Finite element method, Trochanteric fracture, Sliding hip screw, Angulation deformity, Postoperative displacement

\section{Background}

Femoral trochanteric fractures are common among older adults. These fractures are closely related to osteoporosis due to aging and can become a serious public health challenge with the trend of population senility worldwide [1]. Early rigid fixation is necessary for femoral trochanteric fractures, and patients should participate in

\footnotetext{
*Correspondence: nutsuro_ninja@yahoo.co.jp

Department of Orthopaedic Surgery Restorative Medicine of

Neuro-Musculoskeletal System, Fujita Health University, Bantane Hospital,

3-6-10 Otoubashi, Nakagawa-ku, Nagoya, Aichi 454-8509, Japan
}

rehabilitation as soon as possible to reduce the complications associated with long-term immobilization [2].

A variety of implants have been used for internal fixation of femoral trochanteric fractures. Recently, plates and sliding screws have been the most commonly used implants for fixation and are currently the gold standard [3-5]. In our clinical cases, we used a sliding hip screw (SHS) mounted on a $135^{\circ}$ three-hole side-plate device. This device was designed in such a way that impaction at the fracture site was controlled by the gliding screw [6], and stable contact at the fracture site was acquired

(C) The Author(s). 2018 Open Access This article is distributed under the terms of the Creative Commons Attribution 4.0 International License (http://creativecommons.org/licenses/by/4.0/), which permits unrestricted use, distribution, and 
during the postoperative period [7]. Controlled fracture impaction occurs when SHS contributes to axial and torsional stability in addition to sliding capability [8]. Several complications such as fracture collapse, failure of internal fixation, and non-union occur in cases wherein fracture reduction is suboptimal or is not maintained and the sliding effect is not functional [9].

The purpose of reduction of trochanteric fractures is to acquire the support of the anterior cortex at the fracture site on lateral view [10]. The classification of fracture alignments on lateral view is shown in Fig. 1 [11, 12]. Reduction to a "positive" or "neutral" fracture alignment is necessary to acquire anterior cortical support. Reduction to the positive fracture alignment is ideal, as it provides sufficient support of the anterior femoral neck cortex. The most commonly encountered alignment is a reduction to the neutral fracture alignment, and it has been considered clinically acceptable, but postoperative displacement often occurs because of loss of anterior cortical support at the fracture site (i.e., displacement from the neutral fracture alignment to the negative fracture alignment). Several factors have been suggested to cause this postoperative displacement, and fracture alignment with an angulation deformity at the fracture site on lateral view is reported to be one of the main causes of displacement [11] (Fig. 2). We have postulated that unusual loading at the fracture site leads to fracture collapse, subsequent postoperative displacement, and cut-out of the lag screw (i.e., protrusion of the lag screw from the femoral head) in some cases. Therefore, this study aimed to investigate local stress distribution in models with an angulation deformity at the fracture site and to evaluate the risk factors for postoperative displacement using the finite element (FE) method.

\section{Methods}

The study was approved by the ethics committee of Fujita Health University (No. HM18-078). The unaffected femur of a female patient (aged 95 years) was scanned using a computed tomography scanner (Brilliance 64, Philips Medical Systems, Cleveland, OH, USA). A series of images (slice thickness, $1.0 \mathrm{~mm}$ ) of the femur were obtained. These images were imported in the Digital Imaging and Communications in Medicine format and were transferred to Mimics 18 (Materialise, Leuven, Belgium).

The fracture line was set from the upper part of the lesser trochanter to the greater trochanter and displaced two-fragment fracture models with an angulation deformity at the fracture site and a non-displaced two-fragment fracture model were simulated.

Models with an angulation deformity were of two types, one with the proximal fragment directed backward (type A) and the other with the proximal fragment rotated forward from the femoral neck axis (type B). Type A comprised three models in which the angulation angles at the fracture site were set at 10,30 , and $50^{\circ}$. Type B comprised three models in which the rotational angle of the proximal fragment was set at 10,30 , and $50^{\circ}$.

Models of the femur and an SHS mounted on a $135^{\circ}$ three-hole side-plate were combined (Fig. 3). The geometrical dimensions of the SHS were obtained from the implant manufacturer's catalog (Teijin Nakashima Medical Co., Ltd., Okayama, Japan).

Surface errors of the femoral bone models were corrected using 3-matic 11 software (Materialise). After correcting the surface roughness of the models, the models were converted to a primary tetrahedron mesh using HyperMesh software (Altair Engineering, Troy, MI, USA). The numbers of elements and nodes were 158.023 and 39.077, respectively. The FE models, as aforementioned, were imported into MSC Marc 2012 software (Shinjyuku, Tokyo, Japan) for FE analysis.

The material properties of the bone and SHS models were assumed to be linearly elastic and isotropic [1316]. These were simplified models as the bone is nonlinear and anisotropic [17, 18]. The material of SHS was considered to be titanium. The modulus of elasticity was based on the study by Harrigan et al. [19] (Table 1).

Regarding friction coefficients, 0.1 was used for bonebone interactions; 0.1 , for bone-plate of the implant interactions [20]; 0.3, for bone-cortical screw of the

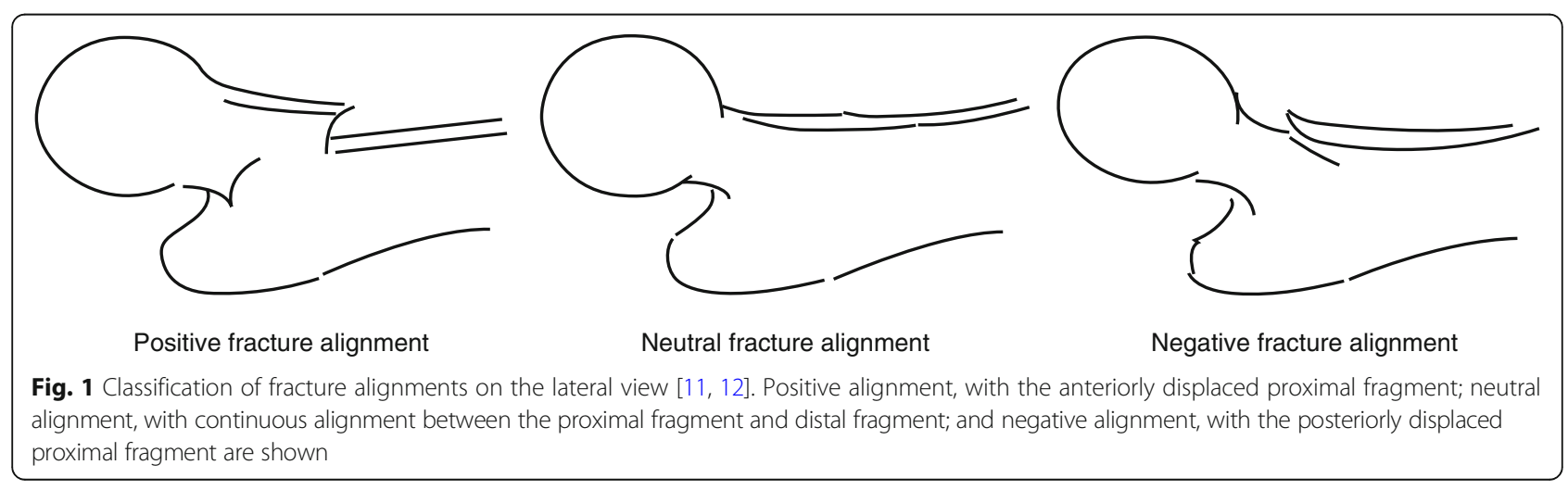




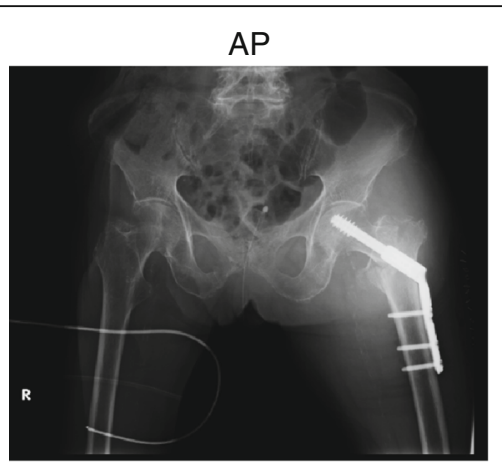

AP

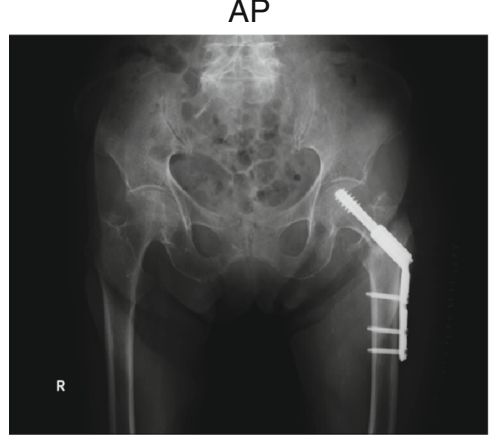

Lateral

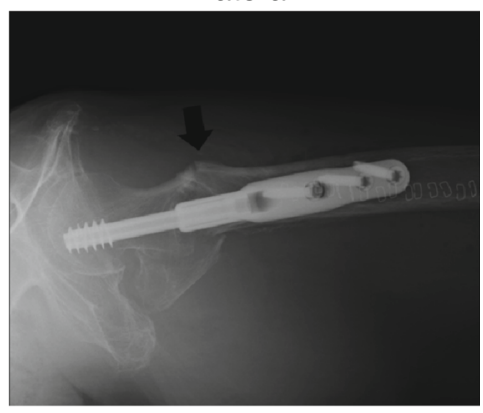

Lateral

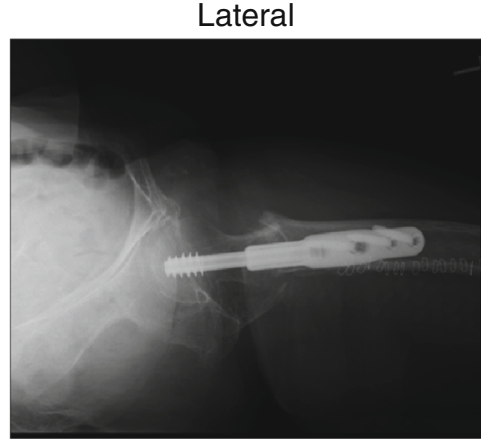

Fig. 2 Postoperative displacement of trochanteric fractures. The upper section shows the postoperative radiograph, confirming reduction to the neutral fracture alignment. The lower section shows a radiograph, obtained on the postoperative day 14, confirming the negative fracture alignment. The black arrow indicates an angulation deformity at the fracture site

implant interactions [21]; and 0.5, for implant-implant interactions.

The applied load condition was based on the study by Akay et al. [22]. A 2010-N load was applied to the femoral head, and a 1086-N load was applied to the greater trochanter. The distal section of the femoral shaft was fully restrained.

In the simulation of these models, the maximum values of the von Mises stress distribution at the medial femoral neck cortex (Fig. 4) and the SHS (Fig. 5) were investigated.

The von Mises stress distribution is a common yield criterion used in the FE method [23]. The stress value corresponds to the equivalent stress, calculated from the principle stress in the three directions ( $X, Y$, and $Z$ axes) [24]. Furthermore, along with the amount of displacement in these three directions, the displacement of the femoral head vertex in the distal direction was also calculated.

\section{Results}

Maximum value of the von Mises stress distribution of the femur

In the simulation of all models, a large stress concentration of the von Mises stress distribution at the medial femoral neck cortex was observed. Compared with the non-displaced two-fragment fracture model, all type A models showed a much larger maximum value of the von Mises stress distribution at this site (Table 2).
Furthermore, models with a larger angulation angle at the fracture site recognized a larger maximum stress value. In type $\mathrm{B}$ models, except the model with a rotational angle of $50^{\circ}$, the maximum stress value at the medial femoral neck cortex was smaller than that in the non-displaced two-fragment fracture model (Table 3).

\section{Maximum value of the von Mises stress distribution of the implant}

In type A models, the maximum stress values at the lag screw, the bottom of the third cortical screw, and the cortical screw-plate interface were larger than those in the non-displaced two-fragment fracture model, except for the maximum stress value at the cortical screw in the model with an angulation angle of $10^{\circ}$ (Table 2 ). In all type $B$ models, the maximum stress values at the lag screw, the bottom of the third cortical screw, and the cortical screwplate interface were a little larger than those in the non-displaced two-fragment fracture model (Table 3).

\section{Amount of displacement of the femoral head vertex in the distal direction}

In all type A models, the femoral head vertex was displaced in the distal direction, and the amount of displacement was higher than that in the non-displaced two-fragment model (Table 4). In all type B models, the femoral head vertex was also displaced in the distal 


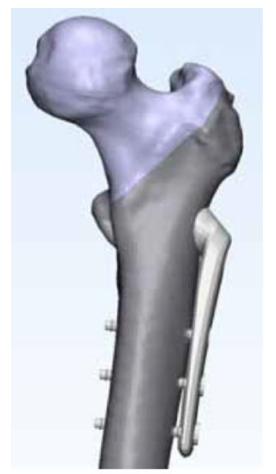

$0^{\circ}$

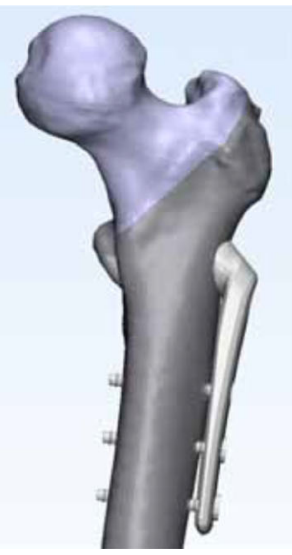

$0^{\circ}$

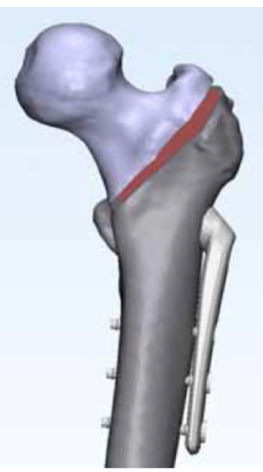

$10^{\circ}$

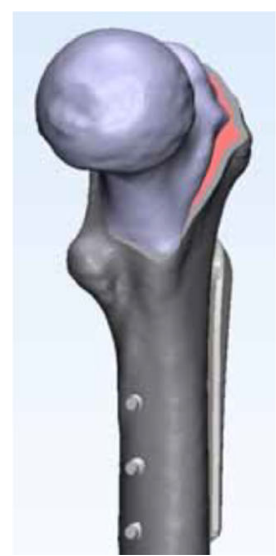

$10^{\circ}$

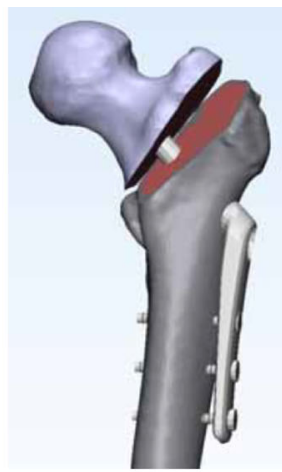

$30^{\circ}$

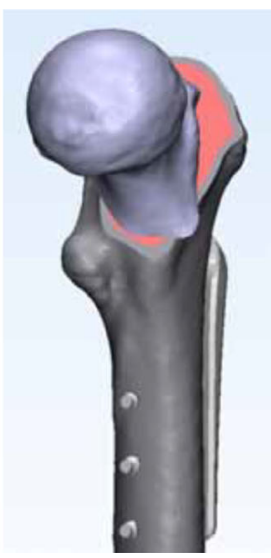

$30^{\circ}$

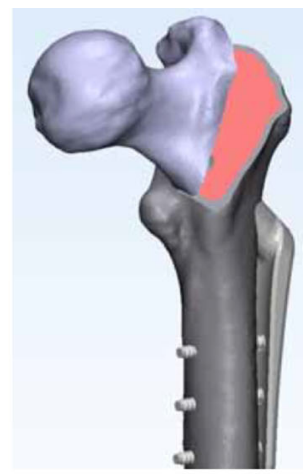

$50^{\circ}$

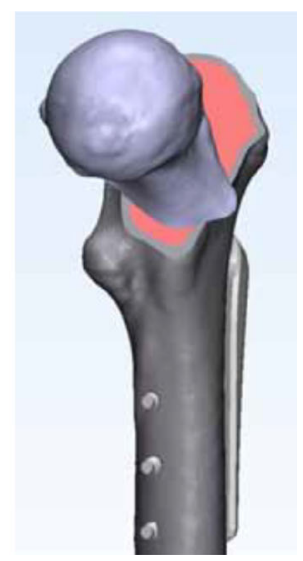

$50^{\circ}$

Fig. 3 Models of the femur and a sliding hip screw. The upper section shows the non-displaced two-fragment fracture model and type A models. The lower section shows the non-displaced two-fragment fracture model and type B models

direction, and the amount of displacement was higher than that in the non-displaced two-fragment model (Table 5). However, the amount of displacement was more marked in type A models.

\section{Discussion}

In the reduction of femoral trochanteric fractures, acquiring the support of the anterior cortex at the fracture site on lateral view immediately after surgery is important. However, even if anterior cortical support is acquired, postoperative displacement due to the loss of this support often occurs. Shiokawa et al. [25] reported a $26 \%$ incidence rate of this postoperative displacement, and we [11] observed a $30 \%$ incidence rate.

Table 1 Material properties of femoral cortical and trabecular bones and the implant

\begin{tabular}{lll}
\hline & Young's modulus (GPa) & Poisson's ratio \\
\hline Titanium (implant) & 110 & 0.3 \\
Cortical bone & 16 & 0.3 \\
Trabecular bone & 1 & 0.3 \\
\hline
\end{tabular}

We [11] indicated that a fracture alignment with an angulation deformity at the fracture site on lateral view radiographs obtained immediately after surgery was a significant risk factor for postoperative displacement and that type A and B fracture alignments were distinguished on the basis of whether the fracture site angulation was easily reduced by pressure from the anterior direction during the intraoperative period. However, in this statistical analysis, fracture alignments with an angulation deformity did not include cases of type A but only included cases of type B. In this study, the relationship between this postoperative displacement and fracture alignments with an angulation deformity, including both type A and B deformities, was examined from the viewpoint of the biomechanics of the FE method.

The FE method has been widely used in biomechanics research. Many situations that would otherwise be difficult or impossible to study in practice can be simulated [13]. Currently, biomechanical analyses of trochanteric fractures and implants are commonly performed [9, 24, 26].

Stress distribution can be analyzed using the FE method by simulating the tissue of origin using discretized FE, setting parameters according to the actual 


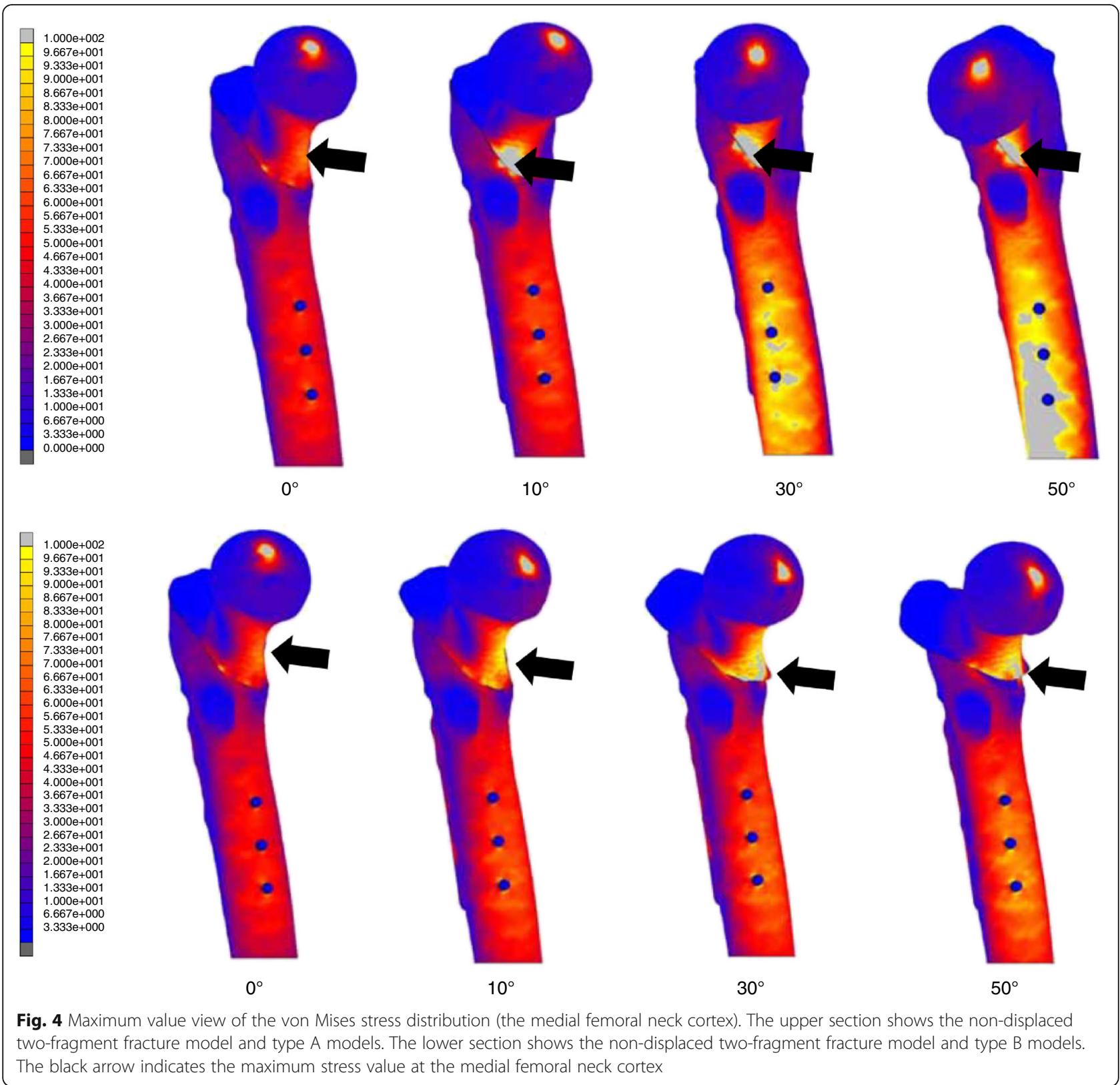

material properties and load conditions, and calculating stress distribution using a computer [24]. If the stress is too large, the element will be damaged and the bone microstructure will be destroyed [24]. The von Mises stress distribution for implants is an indicator of the yielding of metals and can be explained by the mechanics of load sharing [15]. Higher stress value of implants leads to a higher possibility of implant failure [24]. Bone yielding contributes to internal fixation failure if the surrounding bone is weakened by yielding [27]. As a limit state, the failure occurs when elements of implants or the bone are exposed to a load, causing tensions that exceed the yield stress or strength [26]. In our simulation, other criteria such as minimum principal strain from strain analysis of the implant and bone were relatively large between the same types of models. In contrast, the von Mises stress distribution in the implant and bone showed a similar pattern in the same type of models. Therefore, the focus was on the von Mises stress distribution.

In our simulation, a large maximum value of the von Mises stress distribution at the medial femoral neck cortex and a high amount of displacement in the distal direction were especially observed in type A models. In type B models, the maximum stress values were smaller than those in the type A models. These results indicated that microstructural damage was larger in type A models than in type B models and that fracture alignment of type A may be particularly related to fracture collapse 


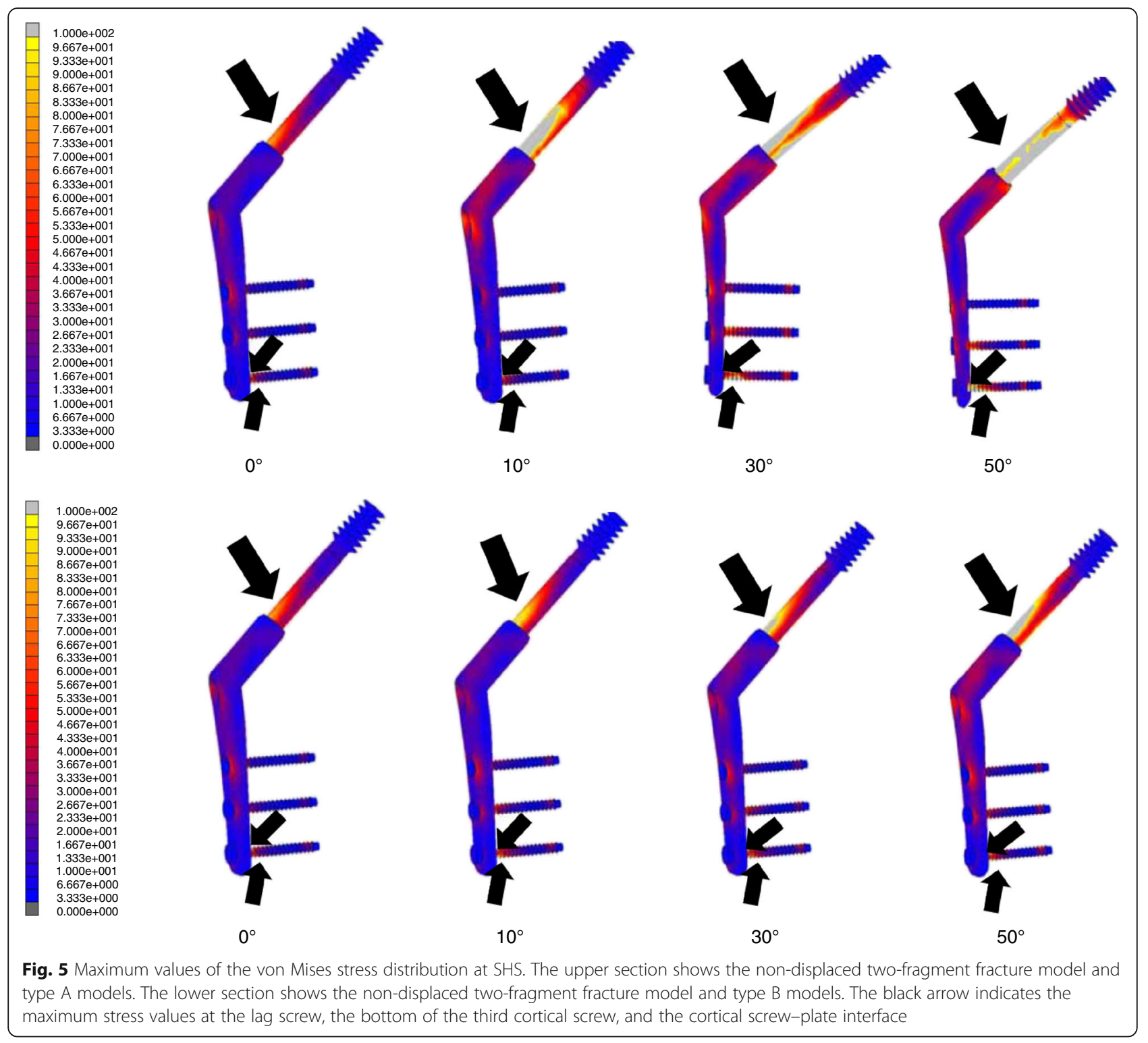

Table 2 Maximum values of the von Mises stress distribution $[\mathrm{MPa}]$ in the non-displaced two-fragment fracture and type $\mathrm{A}$ models

\begin{tabular}{|c|c|c|c|c|}
\hline & $\begin{array}{l}\text { Medial femoral } \\
\text { neck cortex }\end{array}$ & Lag screw & Cortical screw & $\begin{array}{l}\text { Cortical screw- } \\
\text { plate interface }\end{array}$ \\
\hline & [Mpa] & [Mpa] & [Mpa] & [Mpa] \\
\hline$\overline{0^{\circ}}$ & 147 & 260 & 314 & 131 \\
\hline $10^{\circ}$ & 555 & 551 & 276 & 169 \\
\hline $30^{\circ}$ & 620 & 777 & 540 & 230 \\
\hline $50^{\circ}$ & 1031 & 1045 & 854 & 209 \\
\hline
\end{tabular}

Table 3 Maximum values of the von Mises stress distribution $[\mathrm{MPa}]$ in the non-displaced two-fragment fracture and type $\mathrm{B}$ models

\begin{tabular}{lllll}
\hline & $\begin{array}{l}\text { Medial femoral } \\
\text { neck cortex } \\
{[\mathrm{Mpa}]}\end{array}$ & Lag screw & Cortical screw & $\begin{array}{l}\text { Cortical screw- } \\
\text { plate interface } \\
{[\mathrm{Mpa}]}\end{array}$ \\
\hline $0^{\circ}$ & 147 & 260 & 314 & 131 \\
$10^{\circ}$ & 109 & 313 & 426 & 196 \\
$30^{\circ}$ & 135 & 355 & 430 & 208 \\
$50^{\circ}$ & 187 & 454 & 400 & 192 \\
\hline
\end{tabular}


Table 4 Femoral head vertex displacement in the distal direction $[\mathrm{mm}]$ in the non-displaced two-fragment fracture and type A models

\begin{tabular}{ccccc}
\hline & $0^{\circ}$ & $10^{\circ}$ & $30^{\circ}$ & $50^{\circ}$ \\
{$[\mathrm{mm}]$} & {$[\mathrm{mm}]$} & {$[\mathrm{mm}]$} & {$[\mathrm{mm}]$} \\
\hline Displacement & 1.79 & 2.98 & 5.77 & 8.21 \\
\hline
\end{tabular}

and subsequent postoperative displacement. We realized that these results may be due to insufficient bone contact between the proximal and distal fragments in type $\mathrm{A}$, considering the wider bone contact in type $\mathrm{B}$ than in type A. Additionally, in type A, models with a larger angulation angle at the fracture site recognized a larger maximum stress value and a higher amount of displacement in the distal direction. These results may be because of an increase in insufficient bone contact between both fragments in models with a larger angulation angle, and the fracture alignment of these cases indicated an increasing risk of postoperative displacement.

Clinically, the fracture generally affects the bottom of the third cortical screw [24]. The yield strength of the medical titanium alloy is 850 to $900 \mathrm{MPa}$ [28]. Therefore, the maximum stress values at SHS in all models, including both types A and B, except the model with an angulation angle of $50^{\circ}$, were almost in the safety range. In contrast, in the model with an angulation angle of $50^{\circ}$, the maximum stress values at the lag screw and the bottom of the third cortical screw were larger than the above yield strength. This may be because of significant bending of the lag screw due to consequential pressure. Therefore, in the fracture alignment of type A, cases with a striking increase in angulation angle should be warranted for implant failure.

In the FE analysis, preliminarily simulating every situation is impossible and this study has some limitations. In clinical practice, many cases include the medial fragment or the fractured greater trochanter, but we did not simulate fracture lines other than the anterior main fracture line. Furthermore, our mechanical simulation did not consider the factor of placement of the tip of the lag screw in the femoral head. Celik et al. [29] indicated that the position of the lag screw affects the risk of cut-out of the lag screw significantly and that the tip-apex distance [30], that is, the distance from the tip of the lag screw to the apex of the femoral head on anteroposterior and lateral radiographs, was a good predictor of cut-out risk using the FE method.

Table 5 Femoral head vertex displacement in the distal direction $[\mathrm{mm}]$ in the non-displaced two-fragment fracture and type B models

\begin{tabular}{|c|c|c|c|c|}
\hline & $0^{\circ}$ & $10^{\circ}$ & $30^{\circ}$ & $50^{\circ}$ \\
\hline & {$[\mathrm{mm}]$} & {$[\mathrm{mm}]$} & {$[\mathrm{mm}]$} & {$[\mathrm{mm}]$} \\
\hline Displacement & 1.79 & 2.11 & 2.56 & 3.59 \\
\hline
\end{tabular}

Another limitation of our FE analysis is that in our simulation, patient-specific measures of soft tissue thickness or muscle function were not considered. Konstantinidis et al. [31] concluded that muscle forces have little effect on fracture displacement in trochanteric fractures. However, these may be necessary for accurate results in our study. The other limitation is that bone quality (osteoporosis) was not assessed in our FE analysis. Further studies including these factors will be required.

\section{Conclusions}

Our data indicate that mechanical simulation may be useful in the evaluation of factors related to postoperative displacement in trochanteric fractures and that our results can be applied in their clinical treatment. Even if reduction to the neutral fracture alignment is acquired immediately after surgery, caution is needed for cases in which the proximal fragment is directed backward in the postoperative displacement. Furthermore, with regard to fracture alignment, greater caution should be exercised for cases with a larger angulation angle at the fracture site in the postoperative displacement and implant failure.

\section{Abbreviations}

FE: Finite element; SHS: Sliding hip screw

\section{Acknowledgements}

Not applicable

\section{Funding}

No funds were received in support of this study.

\section{Availability of data and materials}

The datasets used and/or analyzed during the current study are available from the corresponding author on reasonable request.

\section{Authors' contribution}

AF performed the translation and adaptation, data analysis, and review and submission and was a major contributor in writing the manuscript. NT performed the study design, manuscript redaction, and review. KM performed the manuscript redaction. All authors read and approved the final manuscript.

Ethics approval and consent to participate

The study was approved by the ethics committee of Fujita Health University (HM18-078). The patient gave her consent to participate in this study.

\section{Consent for publication}

Not applicable

\section{Competing interests}

No benefits in any form have been received or will be received from any commercial party related directly or indirectly to the subject of this article. The authors declare that they have no competing interests.

\section{Publisher's Note}

Springer Nature remains neutral with regard to jurisdictional claims in published maps and institutional affiliations.

Received: 13 September 2018 Accepted: 19 November 2018

Published online: 27 November 2018

References

1. Dhanwal DK, Dennison EM, Harvey NC, Cooper C. Epidemiology of hip fracture: worldwide geographic variation. Indian J Orthop. 2011;45:15-22. 
2. Weller I, Wai EK, Jaglal S, Kreder HJ. The effect of hospital type and surgica delay on mortality after surgery for hip fracture. J Bone Joint Surg Br. 2005; 87:361-6.

3. Luitse J, Dunki Jacobs PB, van der Hart CP. The dynamic hip screw: "golden standard" in the treatment pf pertrochanteric fractures? In: Proximal femoral fractures. Operative techniques and complications. Vol. 2. London: Medical press; 1993. p. 409-22.

4. Barton TM, Gleeson R, Topliss C, Greenwood R, Harries WJ, Chesser TJ. A comparison of the long gamma nail with the sliding hip screw for the treatment of AO/OTA 31-A2 fractures of the proximal part of the femur: a prospective randomized trial. J Bone Joint Surg Am. 2010;92:792-8.

5. Parker MJ, Handoll HH. Gamma and other cephalocondylic intramedullary nails versus extramedullary implants for extracapsular hip fractures in adults. Cochrane Database Syst Rev. 2010;8(9):CD000093.

6. Gupta RK, Sangwan K, Kamboj P, Punia SS, Walecha P. Unstable trochanteric fractures: the role of lateral wall reconstruction. Int Orthop. 2010;34:125-9.

7. Douša $P$, Čech $O$, Weissinger $M$, Džupa $V$. Trochanteric femoral fractures. Acta Chir Orthop Traumatol Cechoslov. 2013;80:15-26.

8. Necas L, Hrubina M, Cibula Z, Behounek J Jr, Krivanek S, Horak Z. Fatique failure of the sliding hip screw - clinical and biomechanical analysis. Comput Methods Biomech Biomed Engin. 2017;20:1364-72.

9. Knobe M, Gradl G, Maier KJ, Drescher W, Jansen-Troy A, Prescher A, et al. Rotationally stable screw-anchor versus sliding hip screw plate systems in stable trochanteric femur fractures: a biomechanical evaluation. J Orthop Trauma. 2013;27:e127-36

10. Sarmiento A. Intertrochanteric fractures of the femur. J Bone Joint Surg. 1963:45:706-22.

11. Furui A, Terada N. Analysis of the postoperative displacement of trochanteric fractures on lateral view radiographs. Acta Med Okayama. 2017; 71:269-77.

12. Ikuta T. Classification of trochanteric fracture of the femur. Kossetsu. 2002;24: 158-62 (in Japanese).

13. Seral B, Garca JM, Cegoino J, Doblare M, Seral F. 3D finite element analysis of the gamma nail and DHS plate in trochanteric hip fractures. Hip Int 2004;14:18-23.

14. Zauel R, Yeni YN, Bay BK, Dong XN, Fyhrie DP. Comparison of the linear finite element prediction of deformation and strain of human cancellous bone to 3D digital volume correlation measurements. J Biomech Eng. 2006; $128: 1-6$

15. Goffin JM, Pankaj P, Simpson AH. The importance of lag screw position for the stabilization of trochanteric fractures with a sliding hip screw: a subjectspecific finite element study. J Orthop Res. 2012;31:596-600.

16. Chen WP, Tai $\mathrm{CL}$, Shih $\mathrm{CH}$, Hsieh PH, Leou MC, Lee MS. Selection of fixation devices in proximal femur rotational osteotomy: clinical complications and finite element analysis. Clin Biomech (Bristol, Avon). 2004;19:255-62.

17. Jacobs CR. Numerical simulation of bone adaptation to mechanical loading. Dissertation for the degree of doctor of Philosophy 1994.

18. Wirtz DC, Schiffers N, Pandorf T, Radermacher K, Weichert D, Forst R. Critical evaluation of known bone material properties to realize anisotropic FEsimulation of the proximal femur. J Biomech. 2000;33:1325-30.

19. Harrigan TP, Kareh JA, O'Connor DO, Burke DW, Harris WH. A finite element study of the initiation of failure of fixation in cemented femoral total hip components. J Orthop Res. 1992;10:134-44.

20. Shirazi-Adl A, Dammak M, Paiement G. Experimental determination of friction characteristics at the trabecular bone/porous-coated metal interface in cementless implants. J Biomed Mater Res. 1993;27:167-75.

21. Viceconti M, Muccini R, Bernakiewicz M, Baleani M, Cristofolini L. Largesliding contact elements accurately predict levels of bone-implant micromotion relevant to osseointegration. J Biomech. 2000;33:1611-8.

22. Akay M, Aslan N. Numerical and experimental stress analysis of a polymeric composite hip joint prosthesis. J Biomed Mater Res. 1996;31:167-82.

23. Pan $\mathrm{H}$, Chen B, Deng LF. Biomechanical effects of the Coflex implantation on the lumbar spine. A nonlinear finite element analysis. Saudi Med J. 2010; 31:1130-6.

24. Yuan GX, Shen YH, Chen B, Zhang WB. Biomechanical comparison of internal fixations in osteoporotic intertrochanteric fracture. A finite element analysis. Saudi Med J. 2012:33:732-9.

25. Shiota N, Sato T, Tetsunaga T, Yoshida M, Mochizuki Y, Yamada K, et al. Evaluation of intraoperative reduction for femoral intertrochanteric fractures. Kossetsu. 2013:35:345-8 (in Japanese).
26. Hrubina M, Horak Z, Skotak M, Letocha J, Baca V, Dzupa V. Assessment of complications depending on the sliding screw position - finite element method analysis. Bratisl Lek Listy. 2015;116:302-10.

27. Goffin JM, Pankaj P, Simpson AH. A computational study on the effect of fracture intrusion distance in three- and four-part trochanteric fractures treated with Gamma nail and sliding hip screw. J Orthop Re. 2014;32:39-45.

28. Long M, Rack HJ. Titanium alloys in total joint replacement--a materials science perspective. Biomaterials. 1998;19:1621-39.

29. Celik T, Mutlu I, Ozkan A, Kisioglu Y. Comparison of the lag screw placements for the treatment of stable and unstable intertrochanteric femoral fractures regarding trabecular bone failure. J Med Eng. 2016:22.

30. Baumgaertner MR, Curtin SL, Lindskog DM, Keggi JM. The value of the tipapex distance in predicting failure of fixation of peritrochanteric fractures of the hip. J Bone Joint Surg Am. 1995;77:1058-64.

31. Konstantinidis L, Papaioannou C, Hirschmüller A, Pavlidis T, Schröter S, Südkamp NP, et al. Effects of muscle-equivalent forces on the biomechanical behavior of proximal femur fracture models: a pilot study on artificial bones. Proc Inst Mech Eng H. 2012;226:681-5.
Ready to submit your research? Choose BMC and benefit from:

- fast, convenient online submission

- thorough peer review by experienced researchers in your field

- rapid publication on acceptance

- support for research data, including large and complex data types

- gold Open Access which fosters wider collaboration and increased citations

- maximum visibility for your research: over $100 \mathrm{M}$ website views per year

At BMC, research is always in progress.

Learn more biomedcentral.com/submissions 